\title{
Employers' perspectives of including young people with disabilities in the workforce, disability disclosure and providing accommodations
}

\author{
Sally Lindsay, Elaine Cagliostro, Joanne Leck, Winny Shen \& \\ Jennifer Stinson
}

Version Pre-print

Citation Lindsay, S., Cagliostro, E., Leck, J., Shen, W., \& Stinson, J. Employers' (published version) perspectives of including young people with disabilities in the workforce, disability disclosure and providing accommodations. Journal of Vocational Rehabilitation, (Preprint), 1-16.

Publisher's Statement The final publication is available at IOS Press through http://dx.doi.org/10.3233/JVR-180996.

How to cite TSpace items

Always cite the published version, so the author(s) will receive recognition through services that track citation counts, e.g. Scopus. If you need to cite the page number of the author manuscript from TSpace because you cannot access the published version, then cite the TSpace version in addition to the published version using the permanent URI (handle) found on the record page.

This article was made openly accessible by $U$ of $T$ Faculty. Please tell us how this access benefits you. Your story matters. 


\title{
Employers' perspectives of including young people with disabilities in the workforce, disability disclosure and providing accommodations
}

\author{
Sally Lindsay ${ }^{\mathrm{a}, b^{*}}$, Elaine Cagliostro ${ }^{\mathrm{b}}$, Joanne Leck $^{\mathrm{c}}$, Winny Shen ${ }^{\mathrm{d}} \mathrm{Jennifer} \mathrm{Stinson}^{\mathrm{e}}$ \\ a Department of Occupational Science and Occupational Therapy, University of Toronto, Toronto, ON, Canada \\ ${ }^{\mathrm{b}}$ Bloorview Research Institute, Holland Bloorview Kids Rehabilitation Hospital, Toronto, ON, Canada \\ ${ }^{c}$ Department of Human Resource Management and Organizational Behaviour, Telfer School of Management, University of \\ Ottawa, Ottawa, ON, Canada \\ ${ }^{\mathrm{d}}$ Department of Psychology, University of Waterloo, Waterloo, ON, Canada \\ e Lawrence Bloomberg Faculty of Nursing and Hospital for Sick Children, Toronto, ON, Canada
}

CONTACT: Sally Lindsay slindsay@hollandbloorview.ca ; 150 Kilgour Road, Toronto, Ontario M4G 1R8, Canada. Tel: (416)- 425-6220 x3654 Fax: (416) 425-1634.

Citation: Lindsay, S., Cagliostro, E., Leck, J., Shen, W., \& Stinson, J. Employers' perspectives of including young people with disabilities in the workforce, disability disclosure and providing accommodations. Journal of Vocational Rehabilitation, (Preprint), 1-16.

Link: https://content.iospress.com/articles/journal-of-vocational-rehabilitation/jvr180996 
Lindsay et al. Employers' perspectives of including YWD

\title{
Employers' perspectives of including young people with disabilities in the workforce, disability disclosure and providing accommodations
}

\begin{abstract}
BACKGROUND: Enhancing the employment of people with disabilities can help support healthy and productive work.
\end{abstract}

OBJECTIVE: Our objective was to understand employer accommodation practices with youth with disabilities (i.e., as they currently exist and what employers need help with) and how they create an inclusive environment.

METHODS: A descriptive qualitative study was conducted involving in-depth interviews with a purposive sample of 18 employers who hire young people with disabilities. Thematic analysis explored issues related to disclosure, accommodations, and inclusion.

RESULTS: Most employers encouraged youth with disabilities to disclose their condition and emphasized the importance of building trust and rapport. Employers described how and when to provide accommodations, types of accommodations (i.e., formal, informal, physical, and social), and how they addressed unmet needs. Employers' strategies for creating an inclusive workplace culture included: diversity training, addressing stigma and discrimination, open communication, mentoring and advocacy.

CONCLUSIONS: Our findings highlight that most employers hiring youth with disabilities have strategies for encouraging them to disclose their condition and request accommodations, which can help to inform employers who do not hire people with disabilities or have effective strategies in place to support them.

Keywords: youth, employment, vocational rehabilitation, adolescent 
Lindsay et al. Employers' perspectives of including YWD

\section{Introduction}

People with disabilities are often viewed as an untapped pool of skilled workers because they have higher unemployment rates compared to people without disabilities (Araten-Bergman, 2016; Haafkens, Kopnina, Meerman, \& van Dijk, 2011; Heymann, Stein, \& de Elvira Moreno, 2014; Lindsay, 2011). A 2012 Canadian Survey on Disability reported that 49\% of persons aged 25-64 with a disability were employed, compared to $79 \%$ for those in the same age range without a disability (Turcotte, 2014). Despite the growing number of working-age Canadians with a disability, less than $30 \%$ of companies have disability-specific policies and only $18 \%$ of companies offer disability-training programs (Hyland \& Rutigliano, 2013; National Council on Disability, 2007).

Even though there are several benefits to hiring people with disabilities, including enhanced reliability, productivity and lower turnover, many employers are hesitant to do so because they have misconceptions about the cost of accommodations (Burke et al., 2013; Hartnett, Stuart, Thurman, Loy, \& Batiste, 2011; Lindsay, McDougall, \& Sanford, 2014). Efforts to improve job outcomes for people with disabilities include hiring subsidies, vocational programs, and inclusion policies (Deuchert \& Kauer, 2014; Lindsay, Goodfellow, Stergiou-Kita, Kirsh, \& Lero, 2017). In Canada specifically, the Employment Equity Act was introduced in 1986 to help achieve workplace equality and provide opportunities for disadvantaged groups, including individuals with disabilities (Cardillo, 1993). The effectiveness of such supply-side interventions has mixed results, and thus, there is a need to explore more of the demand-side factors, including socio-political and labour market context and employer's motivations for hiring (Araten-Bergman, 2016; Chan et al., 2010; Lindsay, Goodfellow, et al., 2017). For instance, a study by Araten-Bergman (2016) found that manager's attitudes and intentions were 
Lindsay et al. Employers' perspectives of including YWD

weak predictors of hiring people with disabilities, whereas formal diversity and inclusion policies and disability training were significant determinants of hiring people with disabilities. Demand-side inclusive employment approaches, such as improved workplace accommodations, are increasing in prevalence. These practices can help to minimize stigma and discrimination, while improving inclusion (Hernandez et al., 2008; Huang \& Chen, 2015). An inclusive workplace environment refers to accepting and valuing diverse and under-represented groups such as persons with disabilities, women, and immigrants, and promotes integration in the workplace and in the community (Chen, Blankenship, Austin, Cantu, \& Kotbungkair, 2016; Mor Barak, 2015).

Within Ontario Canada, where this study was conducted, workplace accommodations are supported by human rights and accessibility legislation (Davis, 2005; Sanford \& Milchus, 2006). Therefore, all employers (both federally and non-federally legislated) are required to provide reasonable accommodations to all employees with disabilities (Government of Canada, 2015; Human Resources and Skill Development Canada, 2009). Workplace accommodations are adjustments made to the physical, environmental, structural, social, and cognitive aspects of the workplace that can include modified work schedules, adaptive technology, accessible workspaces, modified job roles or tasks, and telecommuting (Allaire, Li, \& LaValley, 2003; Bruyere, Erickson, \& VanLooy, 2004; Lindsay, Cagliostro, \& Carafa, 2017). Accommodations can be provided on a formal, or informal basis depending on the employer, the employee, or context. Formal accommodations refer to supports that are company-sponsored and/or procured through a formal accommodations meeting or discussion with the employer or accessibility team, whereas informal accommodations tend to occur on a more ad hoc basis and typically do not require formal discussions or policies (Florey \& Harrison, 2000; Unger, 1999). 
Lindsay et al. Employers' perspectives of including YWD

Although most workplace accommodations can be provided at little or no cost (Dong, Oire, MacDonald-Wilson, \& Fabian, 2013; Solovieva, Dowler, \& Walls, 2011), less than one in five people with a disability receive accommodations in the workplace, and many people with disabilities are unprepared to disclose their condition or negotiate accommodations at work (Allen \& Carlson, 2003; Brohan et al., 2012; Rumrill, Roessler, \& Denny, 1997; Yelin, Sonneborn, \& Trupin, 2000). Employers often lack knowledge of how to provide accommodations, and what accommodations they should provide to individuals with disabilities (Chen et al., 2016). A recent 2017 study showed that employers are more likely to grant workplace accommodations and see them as reasonable if employers are knowledgeable about disability legislation, have experience working with people with disabilities, and hold positive attitudes towards these individuals (Telwatte, Anglim, Wynton, \& Moulding, 2017). Research also highlights that employers are more willing to provide workplace accommodations to people with visible or physical disabilities rather than invisible or psychological disabilities (Lindsay, Cagliostro, et al., 2017; Prince, 2017; Telwatte et al., 2017). This trend underscores the stigma often associated with certain conditions, such as mental illness, and developmental disabilities. Providing accommodations is important because they can help to enhance employee health and work productivity (Gignac \& Cao, 2009; Kirk-Brown, Van Dijk, Simmons, Bourne, \& Cooper, 2014).

To receive workplace accommodations, people must disclose either their need for accommodations, or disclose their condition. Although there are benefits to disclosing a condition, including creating acceptance, increased company moral, increased job retention and productivity in the workplace, some youth may not want to disclose due to potential negative consequences (Lindsay, Cagliostro, et al., 2017; Solovieva et al., 2011). Disadvantages of self- 
Lindsay et al. Employers' perspectives of including YWD

disclosure include stigma and discrimination, negative attitudes from employers or co-workers, and social isolation (Allen \& Carlson, 2003; Lindsay, Cagliostro, et al., 2017; Lindsay et al., 2013; Reed, Meade, Jarnecke, Rumrill, \& Krause, 2017). Individuals with less or non-visible conditions (e.g. multiple sclerosis), are often unsure about whether to disclose and consider the benefits and potential consequences of doing so (Lindsay, Cagliostro, et al., 2017; Reed et al., 2017). Non-disclosure can lead to unnecessary job loss, unsafe working conditions, and can potentially negatively affect job performance and well-being (Lindsay, Cagliostro, et al., 2017; Lindsay et al., 2013). Although disclosure is complex and personal, facilitators to disclosure include support, education and understanding the legal rights related to workplace accommodations (Reed et al., 2017). Youth and young adults (defined as those 30 years and under) with disabilities may be at particular risk for not receiving workplace accommodations if they are unaware that they need to first disclose to their employer. Given that most youth with disabilities have their school accommodations sorted out for them, they may not realize that it is a different process when they are looking for work (Lindsay et al. 2018)

Our study explores employers' perspectives of providing accommodations and inclusive practices of employing youth with disabilities (YWD). Focusing on youth is important because they have low disability disclosure rates and are at high-risk of not receiving workplace accommodations (Lindsay et al., 2013; Scholl \& Mooney, 2004). Understanding the experiences of employers who work with YWD can highlight the process and benefits of including them in the workforce (Huang \& Chen, 2015; Lindsay, Robinson, Mcdougall, Sanford, \& Adams, 2012). Finally, understanding how employers successfully facilitate and implement disclosure discussions and accommodations in the workplace is critical to creating more inclusive and productive workplaces (Lindsay, Cagliostro, et al., 2017). Enhancing employment opportunities 
Lindsay et al. Employers' perspectives of including YWD

and providing accommodations for YWD can improve health, quality of life, work productivity, and workplace safety (Evans \& Repper, 2000; Gignac \& Cao, 2009; Kirk-Brown et al., 2014; Schartz, Hendricks, \& Blanck, 2006).

Our research addresses several important gaps in the literature. First, there is a lack of research focusing on workplace accommodations for youth and young adults with disabilities (Lindsay, Adams, et al., 2014; Lindsay, Cagliostro, et al., 2017; Lindsay, McDougall, MennaDack, Sanford, \& Adams, 2015; Lindsay et al., 2013). Most research focuses on workplace accommodations among adults. Focusing on youth and young adults is important because this population is new to working and may have different accommodations needs. Further, youth and young adults with disabilities may be more used to having their accommodations negotiated or arranged for them by others in the school setting and, thus, advocating for their own needs may be novel for them (Lindsay et al., 2013). Second, little is known about employers' experiences of providing accommodations to YWD. Most research has focused on their attitudes towards hiring people with disabilities and not their actual practices of hiring and including people with disabilities (Burke et al., 2013; Fraser et al., 2010; Hemphill \& Kulik, 2015). Developing an understanding of disclosure and accommodations experiences can help young workers to succeed in finding and maintaining employment, especially at this critical early stage of their careers (Lindsay, Adams, et al., 2014; Lindsay, Cagliostro, et al., 2017).

We draw on human resource strategies to support diversity, which is important given the gaps in theoretical frameworks on human resource management and disability (Mumby, 2008; Williams \& Mavin, 2012). Research demonstrates that the exclusion of people with disabilities from employment opportunities is linked to the social organization of the labour market rather than individual impairments (Barnes \& Mercer, 2005; Lindsay et al., 2015). There are many 
Lindsay et al. Employers' perspectives of including YWD

potential benefits to a diverse workforce including increased organizational efficiency, effectiveness, profitability, innovation, and return on investment (Cassell, 1996; Shen, Chanda, D'netto, \& Monga, 2009). However, those potential benefits do not accrue from the mere presence of workers with disabilities (Shen et al., 2009). Rather, effectively managing diversity requires employers to recognize and value differences as positive attributes of an organization. Therefore, it is essential for employers to commit to valuing diversity and creating an atmosphere of inclusion (Shen et al., 2009). Human resource management and diversity management personnel are concerned about the well-being and performance of workers. However, little is known about employers' strategies for helping their workers to disclose their condition and request accommodations (Baldridge \& Veiga, 2001). Despite many organizations' stated commitment to diversity, wide discrimination in hiring, pay, and promotion persists (Ren, Paetzold, \& Colella, 2008; Shen et al., 2009).

\section{Methods}

\subsection{Objective and design}

Our objective was to understand how employers accommodate and/or need help with accommodating YWD and how they provide an inclusive environment for this population of workers. Our goal was to develop recommendations to other employers on strategies for encouraging disclosure, providing accommodations and creating an inclusive workplace. We used a qualitative design involving in-depth interviews, which are increasingly used to generate evidence-based guidelines and recommendations (Tan, Stokes, \& Shaw, 2009). We obtained institutional ethical approval and written consent from all participants.

\subsection{Sample and recruitment}


Lindsay et al. Employers' perspectives of including YWD

We purposively sampled 18 employers who intentionally hire YWD (i.e., 30 years and under) and who have best practices to share regarding recruitment, retention, and provision of accommodations for this population. Our sample size was sufficient for a qualitative study aiming to capture employer's experiences (Braun \& Clarke, 2006; Corbin, Strauss, \& Strauss, 2014). We recruited from a range of companies throughout Canada and the United States who are legislated to comply with the Employment Equity Act (e.g., federally regulated private-sector employers, Crown corporations and other federal organizations that have 100+ employees) and employers who are not legislated to comply with the Employment Equity Act (Government of Canada, 2015).

Eligible participants needed to meet the following inclusion criteria to participate in the study: currently an employer, manager, and/or work in human resources with experience in recruiting and hiring YWD (i.e., in competitive, integrated employment). We collaborated with community agencies that help young people with disabilities to find employment to identify eligible employers, and we mailed and emailed flyers and information letters to potential participants. Once connecting with companies, we then asked to speak to the person(s) most knowledgeable about hiring and/or including YWD in their workplace. This varied by company with some having CEOs of smaller companies speaking to us and for others it was human resources personnel or diversity officers. Those interested in participating were screened for inclusion by a research assistant who arranged a time and location for interviewing.

Table 1 here

\subsection{Data collection}

Interviews followed a semi-structured guide and asked about: (1) current practices for enabling disclosure and workplace accommodations for YWD; (2) whether and how employers 
Lindsay et al. Employers' perspectives of including YWD

create an inclusive environment; and (3) how employers attract and retain YWD. We also asked for participants' advice for other employers to interview (see supplemental interview guide). Our interview guide was informed by a recent systematic review conducted by our team in 2017 (Lindsay, Cagliostro, et al., 2017).

A research assistant experienced in qualitative research conducted all of the interviews from November 2016 to June 2017. Interviews lasted between 22 and 57 minutes with an average of 42.6 minutes. One interview was conducted in-person and 17 were conducted over the phone, at the discretion of the participant. Most participants chose to be interviewed over the phone given the distance and also to maximize time efficiency (i.e., employers and HR managers are very busy). Each participant received and signed a written consent form by mail prior to taking part and received a $\$ 10$ gift card, as a token of appreciation of their time (as recommended by our research ethics board).

\subsection{Analysis}

The interviews were audio-recorded, transcribed, and checked for accuracy. Our research questions guided the analysis where we applied an open-coding, thematic approach (Braun \& Clarke, 2006). Two authors (with backgrounds in youth rehabilitation, employment, and transitions) read through all transcripts independently and then compared and contrasted our preliminary list of common themes around disclosure and workplace accommodations. Two additional researchers (with experience in management and industrial/organizational psychology) read a sample of the transcripts and independently developed a list of common themes. The research team then compared and contrasted this list through a team discussion. We split, merged or re-labelled themes until reached consensus with the coding scheme (Braun \& Clarke, 2006; Corbin et al., 2014). Consensus between team members was easily achieved in what the main 
Lindsay et al. Employers' perspectives of including YWD

themes constituted. Minor differences occurred in sub-themes and the organization of themes based on our different disciplinary backgrounds. A research assistant applied the codes to all of the interviews using the qualitative software NVivo 10 (2012) to help organize and retrieve relevant quotes (Elo \& Kyngäs, 2008). We selected representative quotes of each theme to help illustrate employers’ perspectives (Braun \& Clarke, 2006; Krefting, 1991).

We used several strategies to enhance the rigour and dependability of our findings including peer debriefing, keeping an audit trail of decisions, and using thick descriptive quotes to reflect participant's experiences (Braun \& Clarke, 2006). The peer debriefing process involved having informal discussions after each interview and formal team discussions with the research team after all interviews were complete, which helped to enhance the trustworthiness of the findings (Braun \& Clarke, 2006). We also kept a log of decisions made throughout the data analysis process. Finally, our team has extensive experience in vocational rehabilitation, disability disclosure and workplace accommodations.

\section{Results}

First, we outline the demographic characteristics of our sample, and then highlight how employers address disability disclosure and workplace accommodations for youth and young adults. Next, we discuss employers' strategies for including YWD in the workplace.

\subsection{Participant characteristics}

Our sample included 18 employers spanning various industries, including: technical services, retail, public service, financial institutions, professional services, recreation, food services, information services, publishing, employment services, and transportation and warehousing (see Table 1). Participants that we interviewed from these companies (i.e., the person most knowledgeable about inclusive hiring practices) included human resource managers, 
Lindsay et al. Employers' perspectives of including YWD

hiring managers, the head of diversity and inclusion, CEO's, and/or business owners. The size of the companies ranged from less than ten to 500,000+ employees (see Table 1). Company size was determined by number of employees: 1-99 employees is a small business, 100-499 employees is a medium sized business, and large business has 500+ employees (Rispoli, Leung, \& Gibson, 2011). To maintain the confidentiality of employers, we classified them according to Statistics Canada main industry types (2017).

Table 1 here

Eight employers were required to follow the Employment Equity Act, which is a federal legislation in Canada that aims to provide equal employment opportunities to disadvantaged groups (e.g., persons with disabilities, women, aboriginal peoples and visible minorities), and applies to federally regulated industries (Cardillo, 1993; Government of Canada, 2015), while the other ten employers (who were non-federally regulated industries) were not. All participants within our sample all had some experience working with YWD, and six employers disclosed that they had personal experience with disabilities (i.e., either had a disability themselves or a family member with a disability). Three companies hired YWD exclusively, or had specific job roles only for them. The rest of our sample had at least one or more YWD working for them at that company. Job roles for YWD spanned entry-level positions, leadership roles, summer employment, internships, and contractual work. One company (\#9) said that the YWD in their company were all "at a different career stage" across various positions in their organization, and a number of employers (9) said that there were opportunities for YWD to be promoted to higher roles or more permanent jobs.

\subsection{Disability disclosure}

\subsubsection{Building trust and comfort}


Lindsay et al. Employers' perspectives of including YWD

Disability disclosure was an important concern for most employers. Many of them (13) discussed how they encouraged YWD to disclose their condition. To help facilitate disclosure, employers emphasized the importance of building comfort and trust with employees. For example, participant \#17, with a professional services company outlined their strategy for encouraging disclosure:

It's important that people feel comfortable disclosing what they need to disclose so they can operate effectively in the workplace....The strategy is to encourage the creation of an environment through messaging, through the behavior of our leaders, to really try to encourage the creation and to maintain an environment where people can actually see that its genuine when we say that we are open to individuals with all characteristics.

Some employers (8) told us that they perceived youth's decision to disclose resulted from their comfort level and trust they developed with them. For instance, the manager of a retail company (\#14) described the importance of building trust with employees:

There's got to be a level of trust there. If you have a fear of disclosing then there must be something telling you that this isn't the right job for you, or not the right employer. If you don't disclose and the employer finds out, there's a loss of trust there. So, not disclosing a disability is probably a bigger detriment to both sides than disclosing.

Similarly, a manager at a financial institution (\#9) described their strategy for creating trust:

A lot of times for people with disabilities, especially youth...they may be at a stage where they're not comfortable with disclosing yet. So, we want to establish that trusting relationship...We find that holding virtual formats [rather than in-person] are better for building that connection...we hosted two or three virtual events last year for YWD...we 
Lindsay et al. Employers' perspectives of including YWD

talk about what it means to disclose...it's important to showcase success stories [of disclosure].

\subsubsection{Disclosure and disability type}

Employers reported noticing differences in disclosure rates for youth with visible and non-visible disabilities; it was more uncommon for youth with non-visible disabilities to disclose. Another employer, remarked that "there probably is a higher percentage of people with non-visible disabilities that haven't identified themselves...[so we] had published a booklet on non-visible disabilities, which we circulated across the organization to try and de-mystify what that really entails, to encourage people [to disclose]" (\#17). Meanwhile, a representative at a recreation company (\#4) similarly found that youth with physical disabilities were more likely to disclose, although among those with invisible disabilities, it was more common for individuals with anxiety to disclose than those with autism spectrum disorder. This employer mentioned that having representatives from a mental health organization helped train employees which may have enhanced youth's comfort with disclosing.

\subsubsection{Building trust and comfort}

Employers noted that the timing of when YWD disclosed varied. For example, a company (\#4) mentioned that youth often disclosed within their cover letters. Participant \#5 reported that about half of their applicants disclosed before the interview and the other half disclosed during the interview, while some did not disclose at all. Meanwhile, an employer in the public service industry (\#15) said that occasionally "things come out in the resume without them actually disclosing... where some of their past work or volunteer experience may [make you] think this person might have a disability." Two employers mentioned that youth often felt unsure of when and how to disclose, to which one employer (\#16) responded: "It's individual but my 
Lindsay et al. Employers' perspectives of including YWD

main communication point is you don't have to disclose what your disability is, but it would be helpful if you shared what we can do to support you from an accommodations perspective."

Employers thought that the timing of disability disclosure depended on the type of industry and the job role. For example, employers remarked that YWD often disclosed upfront for jobs that required them to have a disability to work. Such organizations specifically hired YWD because they were social advocates and wanted to provide jobs for this group with high unemployment rates. To illustrate, a manager of a transportation and warehousing company (\#6) revealed that "approximately 90-95\% [of YWD] disclose on the application for various disabilities, from a simple answer, to very detailed ones. It's different [for us as a company] because we only hire people with disabilities.” Employers noticed that youth seemed comfortable disclosing to 'disability friendly' companies (i.e., known for being inclusive and accommodating). For example, a company, who actively hires people with disabilities described, "we have a unique perspective, again, people just know. So they just disclose" (\#1).

\subsection{Accommodation strategies}

\subsubsection{Timing of Accommodation}

Employers described how and when to provide accommodations, different types of accommodations, and how to address unmet needs. Several employers (11) had formal accommodation procedures, such as an internal accommodations team (i.e., a department or committee that deals directly with workplace accommodations) or outsourcing an external organization. For example, a team within a public service organization managed accommodation requests online using an assistive technology desk that directly deals with accessible software and technology, and a "centralized accommodations fund for major accommodations... [although] whether or not funding is available through that fund it is still the manager's 
Lindsay et al. Employers' perspectives of including YWD

responsibility to accommodate individuals" (\#15, public service). Larger organizations often had formal processes (e.g., participants \#4, 5, 7, 13, 15, 16). For example, at a recreation company (\#4), when an individual needs accommodations, "we go to our director of access and awareness if we don't feel we are fully equipped to handle [accommodations] to best advantage the applicant...our real focus is about solutions, it's whatever it takes and it's without a fuss". Meanwhile, smaller companies often had informal accommodation processes, such as one employer who does not have a specific accommodations team or process, but provides accommodations on an as needed basis. For example, they said "if somebody is in a wheelchair and we need to raise a counter for a register... we have a whole carpentry department right here" (\#5, recreation).

Some employers offered accommodations during different stages of the employment process, while others offered it on an ongoing basis. For example, many employers offered accommodations during the interview process, before the hiring process, after hiring employees, and during training and orientation. Eight employers described how they revisited accommodations on an ongoing basis. For example, participant \#9 at a financial institution, explained "if the individual changes roles then we would re-do the [accommodations] assessment because every role is different....I receive a follow-up [from disability organization] about once a month and after a while maybe after every 3-6 months." Participant \#1 discussed how all employers should review accommodations on an ongoing basis, stating:

Everyone should be asked has anything changed, is there anything you require differently in the job, are you being facilitated? It should be part of the process so that people are comfortable knowing that they have the opportunity to revisit if they don't disclose from the start...a good employer is going to facilitate that conversation. 
Lindsay et al. Employers' perspectives of including YWD

Another employer (in the finance industry) has an accommodations section on their HR intranet which allows any employee to request accommodations:

You can go in as a new employee, if you've been here a long time and developed a disability...or if you feel that your disability is at a point where you need accommodations, you can go on our accommodations site and make a request (\#16).

This organization has a streamlined process for requesting accommodations at any point of employment, and having an electronic method may make youth more comfortable in requesting accommodations.

\subsubsection{Types of accommodations}

Employers remarked on how the types of accommodations that they provided varied based on the job role, type of company, and disability type. A common accommodation that employers reported involved having an adapted interview process. To illustrate, an employer (\#16) described:

whether it's a room with bright or low lights, or an interview with one person or a panel; whether they have a mobility device or require a sign language interpreter; if they require a verbal assessment opposed to written; anything that is required so they can be their most successful self at the interview.

Meanwhile, some employers provided accommodations in the form of adapted training. For instance, an employer in the food services sector (\#11) had their employees with disabilities perform a work trial to see how they performed in the role as opposed to a structured interview. They mentioned that "for [individuals with disabilities] we offer a little more training [than other employees]." 
Lindsay et al. Employers' perspectives of including YWD

In regards to cost of accommodations, most employers told us that the accommodations they provided cost little, if anything. For example, employers provided flexible schedules to employees, such as working from home, shorter shifts, or providing breaks to manage fatigue. Employers also provided physical accommodations, such as altering desks or doorways, and accessible technology or programs that allowed employees to effectively perform their tasks. For example, a professional services company (\#13) provided physical accommodations, such as "ergonomic keyboard or mouse or a type of desk... and larger accommodations [such as] an automatic door opener for someone in a wheelchair."

Some accommodations involved providing social adjustments, often specifically for neurodiverse employees (i.e. individuals with neurological differences such as autism, dyslexia, etc.)(Rentenbach, Prislovsky, \& Gabriel, 2017). Such accommodations involved structuring job roles, adjusting environments depending on their sensitivities (e.g., noise, light etc.), and training staff on ways to effectively interact with people who are neurodiverse. For example, an employment services company for YWD (\#12) stated "to be accommodating of [YWD] socially goes a long way in helping to create an environment where people are going to be comfortable...rather than changing themselves to be what they're not." Another employer provided an example of social accommodations: "with people who may appear to be on the autism spectrum...the managers and coordinators here would match their comfort and ability and personal interaction with others, and align it with what they do best” (\#4).

\subsubsection{Unmet accommodation requests}

Some employers could not provide certain accommodations to their employees. For example, one company said, "if someone requests an accommodation, then $99 \%$ of the time, we say yes. The only time we don't is when someone is being unreasonable, and it would negatively 
Lindsay et al. Employers' perspectives of including YWD

impact someone else in the organization" (\#6). An additional example included a company (\#1) who matches other employers with YWD for mentorship who gave an instance of an employer who did not want to match with a YWD because they had a fear of dogs and they could not accommodate the individual who needed a guide dog. This particular employer was fearful that the accommodation of the individual who did not want to be paired with the guide dog was prioritized over the accommodation of the individual who required the guide dog for their needs, which they expressed reflects "one of the biggest challenges facing those with disabilities in the workplace" (\#1). Meanwhile, another employer (\#8) mentioned, "if a person has a hard time dealing with stress and can't focus properly in half an hour to do [the practical assessment]; it takes them two hours, it would be difficult for that person to get the position" (\#8, information services). This particular employer hires YWD for entry-level roles, and therefore, the interview process for a more advanced job role would not allow certain accommodations, such as extra time, and thus, it may be more difficult for some YWD to get that position.

\subsection{Inclusion strategies}

Employers had various strategies for creating an inclusive workplace culture, such as diversity training, addressing stigma and discrimination, open communication, mentorship, and advocacy.

\subsubsection{Diversity training}

Employers noted the importance of having diversity training and policies. For instance, 12 employers provided company-wide disability and inclusion training, specific training for coworkers, and/or partnered with disability organizations. Three employers mentioned the importance of training leadership and management to create a top-down approach for inclusion. For instance, one company (\#17) said, "there's no magic wand you can wave to create an 
Lindsay et al. Employers' perspectives of including YWD

inclusive workplace culture...It's an ongoing process...Y ou have to intervene at all levels, starting with your leadership. You have to set the tone at the top." One employer discussed their strategy of accessibility training for co-workers by hosting "webinars and panel events. We're also having some more interactive, fun events [such as] a wheelchair basketball game" (\#13). Employers noted that training co-workers on diversity and inclusion helped to increase understanding and comfort around people with disabilities amongst all employees. For example, one employer who hires youth with autism spectrum disorder mentioned that they provide training for co-workers and managers:

so they have a bit of understanding, not only for the individuals and what they are personally like but more broadly about diversity and autism, and about working with people that are different...we want to create an environment that people can be successful [by] informing and training others who they are going to be working with about what they are like. To be accommodating of them socially goes a long way in helping to create an environment where people are going to be comfortable (\#12).

\subsubsection{Addressing stigma and discrimination}

Employers described how addressing disability-related stigma and discrimination in the workplace can help to create an inclusive environment. Among the employers we interviewed most mentioned that when stigma did occur it often stemmed from customers, through unconscious bias (e.g., streaming YWD in specific roles, segregating jobs). For example, an employer said that they experienced discrimination from clients in the past, "we explained the situation was unacceptable, we addressed the client... and said this is poor behavior...it's illegal but it's also ethically opposed to anything that we stand for and we will no longer support your 
Lindsay et al. Employers' perspectives of including YWD

business" (\#1). Another employer at a non-profit organization discussed how they have dealt with stigma from customers:

the sad thing is that I've never had anyone complain about the people without disabilities. The only one that have had complaints against them are YWD. I don't think that's a coincidence. All of our employees make mistakes, it's how it's dealt with that makes the difference...I'm left with thinking either I can do business with this individual or I can't (\#10).

Although uncommon within our sample, a few employers expressed their own feelings of stigma towards people with disabilities, even if it was unintentional. For example, one employer described how YWD were sometimes seen as more sheltered or inexperienced. To illustrate, they mentioned, "quite often people with disabilities have...more sheltered lives and have had to advocate for themselves, and social skills, are sometimes not at the level as somebody who is able-bodied would be" (\#4). Another employer in the retail industry received government subsidies for hiring YWD, and at times expressed stereotypical views of hiring people with disabilities, which may indicate their reasoning for hiring YWD was due to the subsidies rather than the benefits of hiring YWD. To illustrate, they stated:

I get some kind of compensation because I have to apply more time and effort to get these people up to speed... it takes a bit of time to adapt and get used to without saying 'sorry you're too slow you gotta leave', so it also gives me incentive to keep them and cut them some slack (\#2).

\subsubsection{Open communication}

Open communication was another important factor in creating an inclusive and comfortable workplace environment. For example, an employer (\#16) described: "I find when 
Lindsay et al. Employers' perspectives of including YWD

there's communication, when there's an open environment that's a culture of inclusiveness, which I feel we have at [our company]. Then questions are asked and answers are given. There's an awareness and understanding." Another employer mentioned that they help YWD to feel comfortable by focusing on their strengths and positive aspects. They do this by asking youth: "how will your disability enable you to be a better [employee]. So, trying to focus on their strengths" (\#6). A professional services employer discussed an instance of open communication with employees with disabilities in the design of their new office building: "folks from our accessibility employee resource group went [to the new office] and gave feedback on what they liked and didn't like and that was incorporated...the point is keeping people involved in making the workplace an ongoing inclusive culture" (\#13).

Another employer (\#12) of an employment services company described communicating with employees about employment barriers:

we look for whatever is causing the person not to perform in their role and where there is environmental challenges causing the person to be uncomfortable in their role, then we deal with whatever those things are...we make sure that the manager is understanding and communicating well with the individual.

Other employers mentioned that providing accommodations for YWD required a lot of flexibility and tolerance, such as a retail employer (\#2), who felt that employers "need to give a bit more patience and cut some slack" to training and providing accommodations to employees with disabilities, who may require more time or more or resources.

\subsubsection{Mentorship}


Lindsay et al. Employers' perspectives of including YWD

Providing mentorship for YWD was another strategy that six employers used to create an inclusive workplace. Some employers mentored and supported YWD. For example, a financial institution (\#9) had a mentoring program that paired high performing YWD with executives:

They meet frequently to discuss career goals and also to help them with their networking within the company. If they say they have a career goal the executive might be able to connect them to someone in a specific department...it's been a year and we've got great feedback.

Another form of mentorship that one employer used involved dedicated mentoring days where businesses who were experienced in hiring YWD shared their experiences and success stories with other employers. They shared that this mentoring program showed:

why it is an advantage to hire someone with a disability. Here are the results we are seeing as a business because we are employing a strategy. Here is what we have designed by utilizing the skills and expertise in those we hire, and here's access to individuals who may be a match for an opportunity at your company, now or in the future (\#1).

Having such a mentorship program can benefit employers by giving them the knowledge and strategies to employ youth. At the same time, youth can also benefit from mentorship through networking and potential employment opportunities.

\subsubsection{Advocacy}

Twelve employers advocated for hiring YWD and having an inclusive workplace. They did this through creating outreach programs (e.g., partnering with schools and youth centres; hosting programs for employers on hiring YWD), collaborating with disability organizations, educating youth and employers, and building awareness through inclusion campaigns and disability conferences. For instance, a manager from a financial institution provided a notable 
Lindsay et al. Employers' perspectives of including YWD

example of advocacy where she engaged youth with disabilities through outreach programs and included YWD in working lunches, stating "I have the pizza lunch and coffee chats just with students who have identified as having a disability...I do go into more detail about the accessibility and accommodation at [bank]...talking about the culture at [bank]" (\#16). The founder of a non-for-profit organization explained their company's advocacy model:

We donate all of [our] profits to charities that create jobs for people living with disabilities...we try to find people who are doing innovative, creative programs that are hopefully scalable who are trying to employ YWD, we donate to those charities as well, as an indirect employment creation (\#10).

Finally, a financial institute discussed the ways they increase inclusion in their larger community:

We look at the community, workplace, marketplace, all different angles...to talk about ways to increase diversity and inclusion specific to disability employment throughout our community- that's led to multiple community events. We've brought in nationally renowned speakers for community members to come in and also for our employees to participate in these events to learn about our passion (\#18).

\section{Discussion}

Exploring employer's experiences of working with youth and young adults who have a disability is important because they face unique challenges compared to adults with disabilities and are also at high risk of not receiving workplace accommodations (Lindsay et al. 2018).

Our results show that most employers encouraged YWD to disclose their condition and request accommodations that they felt would help them to remain healthy and productive in the 
Lindsay et al. Employers' perspectives of including YWD

workplace. They did this by building trust and rapport with their employees having open communication and fostering an inclusive environment.

Our findings are consistent with other research showing that employers can foster and encourage disability disclosure by providing adequate and accessible information about job requirements, and creating a safe environment for individuals to discuss their disability (Prince, 2017). Similarly, studies on youth (Lindsay et al. 2018) and adults with disabilities (Prince, 2017) have found that having open communication and inclusive practices are important aspects of providing workplace accommodations. Previous research shows that hiring practices that are inclusive and supportive of people with disabilities, along with partnering with disability organizations can help enhance disability disclosure and requests for accommodations (Gewurtz, Langan, \& Shand, 2016).

Our results indicate that most employers (14) had formal or informal processes (4) to provide workplace accommodations which included a variety of physical and social adaptations. Past research shows that employers with a strong commitment to diversity among the senior leaders often have more promising employment practices (Broughton \& Strebler, 2008; Lindsay, Cagliostro, et al., 2017). Indeed, having sufficient supports and workplace policies can enhance disability disclosure (Munir, Leka, \& Griffiths, 2005).

Our findings highlight that employers' strategies for creating an inclusive workplace culture included: diversity training, addressing stigma and discrimination, open communication, mentoring and advocacy. Many of the employers in our study were passionate advocates of including people with disabilities, mostly because they had personal experience with disability. Research shows that having knowledge about people with disabilities (especially in the form of diversity training) can help to enhance comfort and inclusive attitudes and behaviors of people 
Lindsay et al. Employers' perspectives of including YWD

with disabilities (Lindsay \& Cancelliere, 2017). To illustrate this, a study by Papakonstantinou and Papadopoulos (2017) found that employers had improved attitudes regarding hiring individuals with visual impairments after being exposed to an informational program on visual impairments. Similar to other studies, our findings also indicate that mentoring can be a powerful tool to enhance inclusion of people with disabilities in the workforce (Lindsay, Hartman, \& Fellin, 2016).

Further, addressing stigma is an important aspect of encouraging disability disclosure because people with disabilities are often concerned about employer's perceptions (Gewurtz et al., 2016; Lindsay, Cagliostro, et al., 2017). Providing a supportive workplace is important because employers who accommodate their employees are less likely to have retention issues (Bruyere et al., 2004).

Employers in our study noticed differences in disclosure between YWD who have invisible versus visible disabilities, which is a consistent trend in the literature showing that those with invisible disabilities may encounter more challenges (Lindsay, Cagliostro, et al., 2017). Further attention is needed on disclosure and accommodation processes for those hiring people with invisible disabilities.

A recent systematic review (Lindsay, Cagliostro, et al., 2017) on workplace disclosure and accommodation requests among YWD found that barriers to disability disclosure were found at the individual, employment, and societal levels. Disclosing depended on disability type, severity, self-concept and advocacy skills (Lindsay, Cagliostro, et al., 2017). Meanwhile, industry type, job conditions, amount of supports and communication with employers influenced decision to disclose. Consistent with our findings, other research also shows that the process and timing of how disability should be discussed in the workplace is complex (Lindsay, Cagliostro, 
Lindsay et al. Employers' perspectives of including YWD

et al., 2017). Future research should explore this further with particular attention to how this might vary by employer and disability type.

In reflecting on our theoretical framework, it was evident that employers in our study who embraced diversity and inclusive practices were seen as advocates for YWD and saw the benefits of a diverse workforce. Our results are consistent with human resource research, which claims that the exclusion of YWD does not depend on the individual characteristics, but rather the sociocultural barriers of the labour market itself. Many employers in our study valued the importance of hiring YWD, rather than focusing on the challenges. Our study helps to fill a gap in the literature on employer strategies for encouraging disability disclosure and accommodations requests.

\subsection{Limitations and future directions}

It is important to acknowledge the limitations of this study. First, we included a wide range of employers (profit, non-profit, sizes, industry types) which may influence experience with YWD and also their procedures for providing accommodations and creating an inclusive environment. The heterogeneity of the employers was a result of the relatively small number of organizations who purposively hire YWD, and thus we do not have the perspective of employers who do not purposely hire but still have YWD in the workplace, or the opinions of employers who do not wish to hire YWD at all, which may limit our findings. Future research should explore the impact of job roles, size of company, and industry type on disclosure and accommodation practices. Future studies should also consider whether different formats and methods of disclosing (e.g., in-person versus online) affect disclosure rates and requests for accommodations. Second, our study was limited in that we had a purposive sampling strategy and thus, there is potential response bias where those who had good experiences in working with 
Lindsay et al. Employers' perspectives of including YWD

people with disabilities may have been more inclined to participate. Third, we relied on selfreport of employer's behaviours rather than their actual behaviours. Future studies should consider observing workplace behaviours. Fourth, it is important to note that the types of employment services (e.g., finding employment, practice interviewing, requesting accommodations) that youth with disabilities varies greatly depending on their location, disability type and knowledge of the resources available to them. Accessing such employment services could affect how and when youth disclose and is an area worthy of further investigation. Finally, it would be interesting to measure inclusion and directly compare the perspectives of employers and YWD. Some employers incorrectly equate providing accommodations with being inclusive.

\section{Conclusion}

Our findings highlight that most employers encouraged youth and young adults with disabilities to disclose their condition and the importance of building trust and rapport. Employers reported that the timing of disclosure was often influenced by the nature of the employment and job role. Employers described how and when to provide accommodations, the types of accommodations (i.e., formal, informal, physical and social) they provided, and how they addressed unmet needs of YWD. Employers had various strategies for creating an inclusive workplace culture such as advocacy, mentoring, creating a comfortable environment, addressing stigma and discrimination, and diversity training and policies. Specifically, our findings suggest that formal diversity and inclusion policies in the workplace can enhance disability disclosure in the workplace, as well as increased understanding and inclusion of people with disabilities, and thus should be implemented more widely across all organizations.

Funding: (withheld for blind review) 
Lindsay et al. Employers' perspectives of including YWD

Conflicts of interests: the authors report no conflicts of interest

Ethical approval: was obtained from our hospital research ethics board.

\section{References}

Allaire, S. H., Li, W., \& LaValley, M. P. (2003). Work barriers experienced and job accommodations used by persons with arthritis and other rheumatic diseases. Rehabilitation Counseling Bulletin, 46(3), 147-156.

Allen, S., \& Carlson, G. (2003). To conceal or disclose a disabling condition? A dilemma of employment transition. Journal of Vocational Rehabilitation, 19(1), 19-30.

Araten-Bergman, T. (2016). Managers' hiring intentions and the actual hiring of qualified workers with disabilities. The International Journal of Human Resource Management, 27(14), 1510-1530. doi:10.1080/09585192.2015.1128466

Baldridge, D. C., \& Veiga, J. F. (2001). Toward a greater understanding of the willingness to request an accommodation: Can requesters' beliefs disable the Americans with Disabilities Act? Academy of Management Review, 26(1), 85-99.

Barnes, C., \& Mercer, G. (2005). Disability, work, and welfare: challenging the social exclusion of disabled people. Work, employment and society, 19(3), 527-545. doi:10.1177/0950017005055669

Braun, V., \& Clarke, V. (2006). Using thematic analysis in psychology. Qualitative Research in Psychology, 3(2), 77-101. doi:10.1191/1478088706qp063oa

Brohan, E., Henderson, C., Wheat, K., Malcolm, E., Clement, S., Barley, E. A., . . Thornicroft, G. (2012). Systematic review of beliefs, behaviours and influencing factors associated 
Lindsay et al. Employers' perspectives of including YWD

with disclosure of a mental health problem in the workplace. BMC Psychiatry, 12(1), 11. doi:10.1186/1471-244X-12-11

Broughton, A., \& Strebler, M. (2008). Reaping benefits from diversity. Strategic HR Review, 7(5), 5-10. doi:10.1108/14754390810893035

Bruyere, S. M., Erickson, W. A., \& VanLooy, S. (2004). Comparative Study of Workplace Policy and Practices Contributing to Disability Nondiscrimination. Rehabilitation Psychology, 49(1), 28.

Burke, J., Bezyak, J., Fraser, R. T., Pete, J., Ditchman, N., \& Chan, F. (2013). Employers' attitudes towards hiring and retaining people with disabilities: A review of the literature. The Australian Journal of Rehabilitaton Counselling, 19(1), 21-38. doi:10.1017/jrc.2013.2

Cardillo, B. (1993). Defining and measuring employment equity. Perspectives on Labour and Income,(Statistics Canada, Catalogue 75-001), 5, 43-56.

Cassell, C. (1996). A fatal attraction? Strategic HRM and the business case for women's progression at work. Personnel Review, 25(5), 51-66. doi:10.1108/00483489610130931

Chan, F., Strauser, D., Maher, P., Lee, E.-J., Jones, R., \& Johnson, E. T. (2010). Demand-side factors related to employment of people with disabilities: A survey of employers in the Midwest region of the United States. Journal of Occupational Rehabilitation, 20(4), 412419. doi:10.1007/s10926-010-9252-6

Chen, R. K., Blankenship, C. J., Austin, B. S., Cantu, V. C., \& Kotbungkair, W. (2016). Hiring of people with disabilities: Perceptions of Hispanic small business owners. Journal of Vocational Rehabilitation, 45(2), 185-196. 
Lindsay et al. Employers' perspectives of including YWD

Clark, R. E., Xie, H., Becker, D. R., \& Drake, R. E. (1998). Benefits and costs of supported employment from three perspectives. The Journal of Behavioral Health Services \& Research, 25(1), 22-34. doi:10.1007/BF02287497

Corbin, J., Strauss, A., \& Strauss, A. L. (2014). Basics of qualitative research. Thousand Oaks, CA: Sage.

Davis, L. (2005). Disabilities in the workplace: recruitment, accommodation, and retention. Occupational Health Nursing, 53(7), 306-312.

Deuchert, E., \& Kauer, L. (2014). Hiring subsidies for people with a disability-Evidence from a small scale social field experiment. International Labour Review, 156(2), 269-285. doi:10.1111/j.1564-913X.2014.00025.x

Dong, S., Oire, S. N., MacDonald-Wilson, K. L., \& Fabian, E. S. (2013). A comparison of perceptions of factors in the job accommodation process among employees with disabilities, employers, and service providers. Rehabilitation Counseling Bulletin, 56(3), 182-189. doi:10.1177/0034355212468618

Eggleton, I., Robertson, S., Ryan, J., \& Kober, R. (1999). The impact of employment on the quality of life of people with an intellectual disability. Journal of Vocational Rehabilitation, 13(2), 95-107.

Elo, S., \& Kyngäs, H. (2008). The qualitative content analysis process. Journal of advanced nursing, 62(1), 107-115. doi:10.1111/j.1365-2648.2007.04569.x.

Evans, J., \& Repper, J. (2000). Employment, social inclusion and mental health. Journal of Psychiatric and Mental Health Nursing, 7(1), 15-24. doi:10.1046/j.13652850.2000.00260.x 
Lindsay et al. Employers' perspectives of including YWD

Florey, A. T., \& Harrison, D. A. (2000). Responses to informal accommodation requests from employees with disabilites: Multistudy evidence on willingness to comply. Academy of Management Journal, 43(2), 224-233.

Fraser, R. T., Johnson, K., Hebert, J., Ajzen, I., Copeland, J., Brown, P., \& Chan, F. (2010). Understanding employers' hiring intentions in relation to qualified workers with disabilities: Preliminary findings. Journal of Occupational Rehabilitation, 20(4), 420426.

Gewurtz, R. E., Langan, S., \& Shand, D. (2016). Hiring people with disabilities: A scoping review. Work, 54(1), 135-148. doi:10.3233/WOR-162265.

Gignac, M. A., \& Cao, X. (2009). "Should I tell my employer and coworkers I have arthritis?” A longitudinal examination of self-disclosure in the work place. Arthritis Care \& Research, 61(12), 1753-1761. doi:10.1002/art.24889

Government of Canada. (2015). Legislated Employment Equity Program. Retrieved from http://www.labour.gc.ca/eng/standards_equity/eq/emp/leep/index.shtml

Haafkens, J. A., Kopnina, H., Meerman, M. G., \& van Dijk, F. J. (2011). Facilitating job retention for chronically ill employees: perspectives of line managers and human resource managers. BMC health services research, 11(1), 104. doi:10.1186/1472-696311-104

Hartnett, H. P., Stuart, H., Thurman, H., Loy, B., \& Batiste, L. C. (2011). Employers' perceptions of the benefits of workplace accommodations: Reasons to hire, retain and promote people with disabilities. Journal of Vocational Rehabilitation, 34(1), 17-23. doi:10.3233/JVR2010-0530 
Lindsay et al. Employers' perspectives of including YWD

Hemphill, E., \& Kulik, C. T. (2015). Which Employers Offer Hope for Mainstream Job Opportunities for Disabled People? Social Policy and Society, 15(04), 537-554. doi: $10.1017 / \mathrm{s} 1474746415000457$

Hernandez, B., McDonald, K., Divilbiss, M., Horin, E., Velcoff, J., \& Donoso, O. (2008). Reflections from Employers on the Disabled Workforce: Focus Groups with Healthcare, Hospitality and Retail Administrators. Employee Responsibilities and Rights Journal, 20(3), 157-164. doi:10.1007/s10672-008-9063-5

Heymann, J., Stein, M. A., \& de Elvira Moreno, M. R. (2014). Disability and equity at work. New York, NY: Oxford University Press.

Huang, I.-C., \& Chen, R. K. (2015). Employing people with disabilities in the Taiwanese workplace: Employers' perceptions and considerations. Rehabilitation Counseling Bulletin, 59(1), 43-54. doi:10.1177/0034355214558938

Human Resources and Skill Development Canada. (2009). Advancing the inclusion of people with disabilities. Retrieved from Gatineau, QC: http://publications.gc.ca/collections/collection_2009/rhdcc-hrsdc/HS61-1-2009E.pdf

Hyland, P. K., \& Rutigliano, P. J. (2013). Eradicating discrimination: Identifying and removing workplace barriers for employees with disabilities. Industrial and Organizational Psychology, 6(4), 471-475. doi:10.1111/iops.12087

Kirk-Brown, A., Van Dijk, P., Simmons, R., Bourne, M., \& Cooper, B. (2014). Disclosure of diagnosis of multiple sclerosis in the workplace positively affects employment status and job tenure. Multiple Sclerosis Journal, 20(7), 871-876. doi:10.1177/1352458513513967

Krefting, L. (1991). Rigor in qualitative research: The assessment of trustworthiness. American Journal of Occupational Rehabilitation, 45(3), 214-222. doi:10.5014/ajot.45.3.214 
Lindsay et al. Employers' perspectives of including YWD

Kuiper, L., Bakker, M., \& Van der Klink, J. (2016). The Role of Human Values and Relations in the Employment of People with Work-Relevant Disabilities. Social Inclusion, 4(4), 176. doi:10.17645/si.v4i4.696

Lindsay, S. (2011). Discrimination and other barriers to employment for teens and young adults with disabilities. Disability and rehabilitation, 33(15-16), 1340-1350.

Lindsay, S., Adams, T., Sanford, R., McDougall, C., Kingsnorth, S., \& Menna-Dack, D. (2014). Employers' and employment counselors' perceptions of desirable skills for entry-level positions for adolescents: how does it differ for youth with disabilities? Disability \& Society, 29(6), 953-967.

Lindsay, S., Cagliostro, E., \& Carafa, G. (2017). A systematic review of workplace disclosure and accommodation requests among youth and young adults with disabilities. Disabilty \& Rehabilitation, 1-16. doi:10.1080/09638288.2017.1363824

Lindsay, S., \& Cancelliere, S. (2017). A model for developing disability confidence. Disability and Rehabilitation, 1-9. doi:10.1080/09638288.2017.1326533

Lindsay, S., Goodfellow, A., Stergiou-Kita, M., Kirsh, B., \& Lero, D. (2017). Inclusionary business practices for recruiting and retaining people with disabilities: A scoping review. Physical Disabilities: Perspectives, Risk Factors and Quality of Life. New York, NY: Nova Science Publishers.

Lindsay, S., Hartman, L., \& Fellin, M. (2016). A systematic review of mentorship programs to facilitate transition to post-secondary education and employment for youth and young adults with disabilities. Disability \& Rehabilitation, 38(14), 1329-1349. doi:10.3109/09638288.2015.1092174 
Lindsay et al. Employers' perspectives of including YWD

Lindsay, S., McDougall, C., Menna-Dack, D., Sanford, R., \& Adams, T. (2015). An ecological approach to understanding barriers to employment for youth with disabilities compared to their typically developing peers: Views of youth, employers, and job counselors. Disability and Rehabilitation, 37(8), 701-711. doi:10.3109/09638288.2014.939775.

Lindsay, S., McDougall, C., \& Sanford, R. (2013). Disclosure, accommodations and self-care at work among adolescents with disabilities. Disability \& Rehabilitation, 35(26), 22272236. doi:10.3109/09638288.2013.775356

Lindsay, S., McDougall, C., \& Sanford, R. (2014). Exploring Supervisors' Attitudes of Working with Youth Engaged in an Inclusive Employment Training Program. Journal of Human Development, Disability and Social Change, 12-20.

Lindsay, S., Robinson, S., Mcdougall, C., Sanford, R., \& Adams, T. (2012). Employers’ perspectives of working with adolescents with disabilities. International Journal of Disability Community \& Rehabilitation, 11(1).

Mor Barak, M. E. (2015). Inclusion is the key to diversity management, but what is inclusion? Human Service Organizations: Management, Leadership \& Governance, 39(2), 83-88.

Mumby, D. (2008). Theorizing the future of critical organization studies. New Approaches in Management and Organization. London: Sage, 27-28.

Munir, F., Leka, S., \& Griffiths, A. (2005). Dealing with self-management of chronic illness at work: predictors for self-disclosure. Social Science \& Medicine, 60(6), 1397-1407. doi:10.1016/j.socscimed.2004.07.012

National Council on Disability. (2007). Empowerment for Americans with Disabilities: Breaking barriers to careers and full employment. Retrieved from National Council on Disability's website: $\underline{\text { htps://ncd.gov/publications/2007/Oct2007 }}$ 
Lindsay et al. Employers' perspectives of including YWD

NVivo. (2012). Qualitative data analysis software. QSR International Pty Ltd (Version 10).

Owen, F., Li, J., Whittingham, L., Hope, J., Bishop, C., Readhead, A., \& Mook, L. (2015). Social Return on Investment of an Innovative Employment Option for Persons with Developmental Disabilities. Nonprofit Management and Leadership, 26(2), 209-228. doi: $10.1002 / \mathrm{nml} .21187$

Papakonstantinou, D., \& Papadopoulos, K. (2017). The impact of information on employers' attitudes towards employees with visual impairments. Journal of Vocational Rehabilitation, 47(1), 99-107.

Prince, M. J. (2017). Persons with invisible disabilities and workplace accommodation: Findings from a scoping literature review. J Vocat Rehabil, 46(1), 75-86. doi:10.3233/JVR-160844

Reed, K. S., Meade, M., Jarnecke, M., Rumrill, P., \& Krause, J. S. (2017). Disclosing disability in the employment setting: Perspectives from workers with multiple sclerosis. Journal of Vocational Rehabilitation, 47(2), 175-184.

Ren, L. R., Paetzold, R. L., \& Colella, A. (2008). A meta-analysis of experimental studies on the effects of disability on human resource judgments. Human Resource Management Review, 18(3), 191-203. doi:10.1016/j.hrmr.2008.07.001

Rentenbach, B., Prislovsky, L., \& Gabriel, R. (2017). Valuing differences: Neurodiversity in the classroom: Drawing on their own experiences as students, researchers, and educators, the authors discuss how teachers can build on the skills and talents of neurodiverse learners. Phi Delta Kappan, 98, 59. doi:10.1177/0031721717708297

Rispoli, L., Leung, D., \& Gibson, B. (2011). Small, Medium-Sized and Large Businesses in the Canadian Economy: Measuring their Contribution to Gross Domestic Product in 2005. 
Lindsay et al. Employers' perspectives of including YWD

Ottawa, CA: Statistics Canada. Retrieved from http://www.statcan.gc.ca/pub/11f0027m/11f0027m2011069-eng.pdf.

Rumrill, P., Roessler, R., \& Denny, G. (1997). Increasing confidence in the accommodation request process among persons with multiple sclerosis: A career maintenance selfefficacy intervention. Journal of Job Placement, 13(3), 5-9.

Sanford, J. A., \& Milchus, K. (2006). Evidence-based practice in workplace accommodations. Work, 27(4), 329-332.

Schartz, H. A., Hendricks, D., \& Blanck, P. (2006). Workplace accommodations: Evidence based outcomes. Work, 27(4), 345-354.

Scholl, L., \& Mooney, M. (2004). Youth with Disabilities in Work-Based Learning Programs: Factors that Influence Success. Journal for Vocational Special Needs Education, 26, 416.

Shen, J., Chanda, A., D'netto, B., \& Monga, M. (2009). Managing diversity through human resource management: An international perspective and conceptual framework. The International Journal of Human Resource Management, 20(2), 235-251. doi:10.1080/09585190802670516

Solovieva, T. I., Dowler, D. L., \& Walls, R. T. (2011). Employer benefits from making workplace accommodations. Disability and Health Journal, 4(1), 39-45. doi:10.1016/j.dhjo.2010.03.001

Statistics Canada. (2017). North American Industry Classification System Canada. Retrieved from https://www.statcan.gc.ca/pub/12-501-x/12-501-x2016002-eng.pdf

Tan, T. P., Stokes, T., \& Shaw, E. J. (2009). Use of qualitative research as evidence in the clinical guideline program of the National Institute for Health and Clinical Excellence. 
Lindsay et al. Employers' perspectives of including YWD

International Journal of Evidence-Based Healthcare, 7(3), 169-172. doi:10.1111/j.17441609.2009.00135.x.

Telwatte, A., Anglim, J., Wynton, S. K., \& Moulding, R. (2017). Workplace accommodations for employees with disabilities: A multilevel model of employer decision-making. Rehabilitation Psychology, 62(1), 7. doi:10.1037/rep0000120

Turcotte, M. (2014). Persons with disabilities and employment. Ottawa, CA Statistics Canada. Retrieved from http://www.statcan.gc.ca/pub/11f0027m/11f0027m2011069-eng.pdf.

Unger, D. D. (1999). Workplace supports: A view from employers who have hired supported employees. Focus on Autism and other developmental disabilities, 14(3), 167-179. doi:10.1177/108835769901400306

Williams, J., \& Mavin, S. (2012). Disability as constructed difference: A literature review and research agenda for management and organization studies. International Journal of Management Reviews, 14(2), 159-179. doi:10.1111/j.1468-2370.2012.00329.x

Yelin, E., Sonneborn, D., \& Trupin, L. (2000). The prevalence and impact of accommodations on the employment of persons 51-61 years of age with musculoskeletal conditions. Arthritis care and research, 13(3), 168-176. doi:10.1002/15290131(200006)13:3<168::AID-ANR6>3.0.CO;2-R 
Table 1

Overview of sample characteristics

\begin{tabular}{|c|c|c|c|c|c|c|c|}
\hline $\begin{array}{c}\text { ID } \\
\#\end{array}$ & Industry Type & Job Role & $\begin{array}{l}\text { Employment } \\
\text { Equity }\end{array}$ & $\begin{array}{c}\text { Size of } \\
\text { Company }\end{array}$ & $\begin{array}{l}\text { Disclosure / } \\
\text { accommodation } \\
\text { strategies }\end{array}$ & Inclusion strategies & $\begin{array}{l}\text { Recruitment } \\
\text { strategy for hiring } \\
\text { YWD }\end{array}$ \\
\hline$\# 1$ & Technical services & Vice President & No & Small & $\begin{array}{l}\text {-Encourage; building } \\
\text { trust; open } \\
\text { communication }\end{array}$ & $\begin{array}{l}\text {-Advocacy; } \\
\text { training; mentoring; } \\
\text { making youth } \\
\text { comfortable }\end{array}$ & $\begin{array}{l}\text {-None; well known } \\
\text { as being inclusive }\end{array}$ \\
\hline \#2 & Retail & Store Owner & No & Small & $\begin{array}{l}\text {-Open } \\
\text { communication; } \\
\text { patience }\end{array}$ & $\begin{array}{l}\text {-Confused with } \\
\text { accommodations; } \\
\text { making youth } \\
\text { comfortable }\end{array}$ & $\begin{array}{l}\text {-Disability } \\
\text { employment } \\
\text { programs }\end{array}$ \\
\hline \#3 & Publishing & $\begin{array}{l}\text { Advertising } \\
\text { Manager }\end{array}$ & No & Large & $\begin{array}{l}\text {-Accommodations } \\
\text { team }\end{array}$ & $\begin{array}{l}\text {-Training; } \\
\text { mentoring; making } \\
\text { youth comfortable }\end{array}$ & -None \\
\hline \#4 & Recreation & $\begin{array}{c}\text { Director of Human } \\
\text { Resources }\end{array}$ & No & Large & $\begin{array}{l}\text {-Encourage; building } \\
\text { trust; open } \\
\text { communication; } \\
\text { accommodations }\end{array}$ & $\begin{array}{l}\text {-Advocacy; } \\
\text { training; making } \\
\text { youth comfortable }\end{array}$ & $\begin{array}{l}\text {-Known for being } \\
\text { inclusive; external } \\
\text { organizations; } \\
\text { University }\end{array}$ \\
\hline
\end{tabular}


Lindsay et al. Employers' perspectives of including YWD

\#5

$$
\text { Recreation }
$$

Recruitment

Manager

\#6

Transportation
and warehousing

Operations

Manager

\#7

Food Services

Director

Yes

Large

\#8

Information

services

\#9
Finance
No

No

Small

Supervisor

Yes

Small

Large
-Encourage; building

trust; patience

-Accommodations

team

-Open

communication;

patience

Yes

Diversity and

Inclusion

$\begin{array}{lll}\text {-Encourage; } & \text {-Training; making } & \text {-Known for being } \\ \text { accommodations } & \text { youth comfortable } & \text { inclusive; } \\ \text { team } & & \text { organizations come } \\ & & \text { to them } \\ \text {-Encourage; building } & \text {-Training; making } & \text {-Posting ads; } \\ \text { trust; patience } & \text { youth comfortable } & \text { known for being } \\ & & \text { inclusive } \\ \text {-Accommodations } & \text {-Advocacy; } & \text {-Youth work } \\ \text { team } & \text { training; making } & \text { program } \\ & \text { youth comfortable } & \\ \text {-Open } & \text {-Training; making } & \text {-External } \\ \text { trust; } & \text { youth comfortable } & \text { employment } \\ \text { accommodations } & \text { making youth } & \text { with disability } \\ \text { patience } & & \text { program } \\ \text {-Encourage; building } & \text {-Advocacy; } & \text {-Campus } \\ & \text { mentoring; training; } & \text { recruitment, partner } \\ & & \end{array}$

team 
Lindsay et al. Employers' perspectives of including YWD

\begin{tabular}{|c|c|c|c|c|c|c|c|}
\hline & & & & & team & comfortable & agencies \\
\hline \multirow[t]{2}{*}{ \#10 } & Non-profit & Founder/Executive & No & Small & -Encourage; open & -Advocacy; making & -Known for being \\
\hline & organization & Director & & & communication & youth comfortable & inclusive; referrals \\
\hline \multirow[t]{3}{*}{ \#11 } & Food services & Owner & No & Small & & -Advocacy; & -known for being \\
\hline & & & & & & training; making & inclusive; referrals; \\
\hline & & & & & & youth comfortable & organization \\
\hline \multirow[t]{3}{*}{$\# 12$} & Employment & $\mathrm{CEO}$ & No & Large & -Encourage; building & -Advocacy; & -Community \\
\hline & services & & & & trust; open & training; making & organizations; \\
\hline & & & & & communication & youth comfortable & social media \\
\hline \multirow[t]{4}{*}{$\# 13$} & Professional & Manager, & Yes & Large & -Encourage; open & -Advocacy; & -University \\
\hline & services & Accessibility and & & & communication; & training; making & recruitment; intake \\
\hline & & Inclusion & & & accommodations & youth comfortable & \\
\hline & & & & & team & & \\
\hline \multirow[t]{4}{*}{$\# 14$} & Retail & Store Manager & No & Medium & -Encourage; building & -Advocacy & -Job training \\
\hline & & & & & trust; open & & agencies; schools; \\
\hline & & & & & communication; & & government \\
\hline & & & & & accommodations & & agencies \\
\hline
\end{tabular}


Lindsay et al. Employers' perspectives of including YWD

\#15 Public Service

Head, Inclusion

Unit

\#16

Finance

Manager of Talent

Yes

Acquisition

\#17

Professional

services

Associate Director

Yes

of Human

Resources

\#18

Yes

-Encourage; building

$\begin{array}{cc}\text { Employment and } & \text { Yes (US } \\ \text { Outreach } & \text { company) } \\ \text { Specialist } & \end{array}$

-Encourage;

accommodations

team
Large

trust; open

communication;

accommodations

team

Large

trust; open

communication;

accommodations

team

Large

-Encourage;

accommodations

team

Large
-Mentoring;

training; making

youth comfortable

organizations

-Schools;

-University mentoring; training; recruitment; making youth

referrals;

employment

programs

-University

recruitment

youth comfortable

-Advocacy;

-University

mentoring; training; recruitment;

making youth

community

comfortable community 
Lindsay et al. Employers' perspectives of including YWD

coaches)

${ }^{a}$ Small (1-99 employees), Medium (100-499 employees), Large (500+ employees) 